\title{
Stasis microangiopathy: from pathogenesis to treatment
}

\author{
Salvino Bilancini ${ }^{1}$, Massimo Lucchi ${ }^{1}$, Marco Ciacciarelli ${ }^{2}$ \\ 1J.F. Merlen Research Center for vascular diseases, via Mola Vecchia 4, Frosinone 03100, Italy. \\ ${ }^{2}$ Department of Medico-Surgical Sciences and Biotechnologies, Internal Medicine Unit, ICOT Hospital, "Sapienza" University of \\ Rome, Via Franco Faggiana 1668, Latina 04100, Italy.
}

Correspondence to: Dr. Marco Ciacciarelli, Department of Medico-Surgical Sciences and Biotechnologies, Internal Medicine Unit, ICOT Hospital, “Sapienza” University of Rome, Via Franco Faggiana 1668, Latina 04100, Italy. E-mail:

marco.ciacciarelli@uniroma1.it

How to cite this article: Bilancini S, Lucchi M, Ciacciarelli M. Stasis microangiopathy: from pathogenesis to treatment. Vessel Plus 2021;5:39. https://dx.doi.org/10.20517/2574-1209.2021.14

Received: 27 Jan 2021 First Decision: 10 Feb 2021 Revised: 18 Feb 2021 Accepted: 3 Mar 2021 Published: 11 Jul 2021

Academic Editor: Alexander D. Verin Copy Editor: Yue-Yue Zhang Production Editor: Yue-Yue Zhang

\begin{abstract}
Stasis microangiopathy includes all the pathological changes in the microcirculation and interstitium due to venous hypertension. Venous valve incompetence occurring in the superficial or deep venous system or in both is the most common cause of venous hypertension, a pathological condition that plays a key role in most or all clinical signs of chronic venous disease, including edema and venous ulcers. The aim of the first and main part of this review is to focus on the various pathogenetic mechanisms of stasis microangiopathy triggered by venous hypertension, including hemodynamic and hemorheological alterations, inflammation, and functional alterations. The rationale underlying the current available treatment options of stasis microangiopathy is mentioned briefly in the second part of the review.
\end{abstract}

Keywords: Stasis microangiopathy, microcirculation, venous hypertension, chronic venous disease, venous ulcer

\section{INTRODUCTION}

The term stasis microangiopathy was coined by J.F. Merlen in $1984^{[1]}$ to define all the pathological changes in the microcirculation and interstitium. The entire microcirculation is affected, at the arteriolar, venular, capillary, and lymphatic level. Venous hypertension represents the starting point of the cascade of pathogenetic events [Figure 1]. In most cases, it is caused by reflux through incompetent valves occurring in 


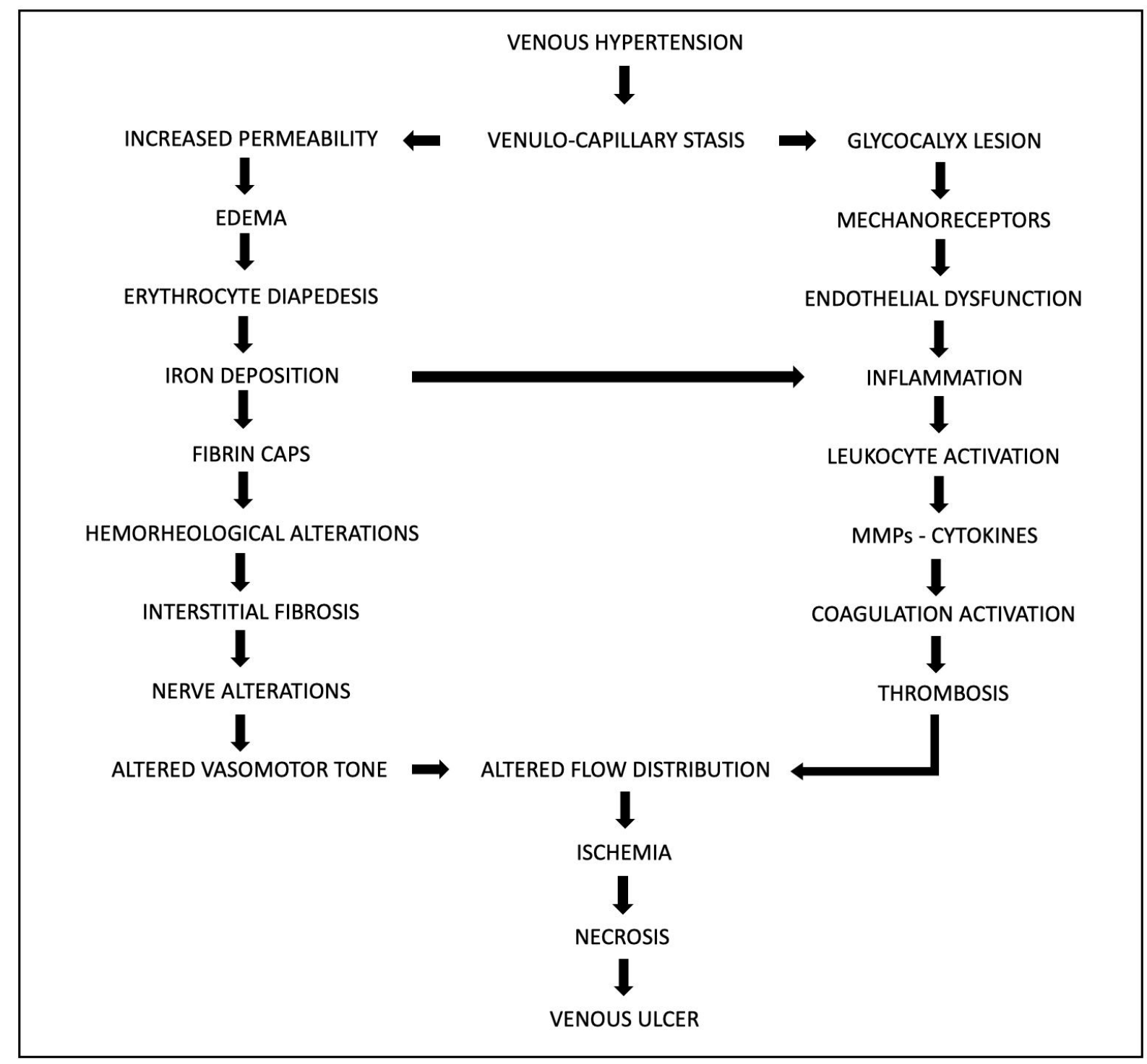

Figure 1. Pathogenesis of stasis microangiopathy. MMPs, matrix metalloproteinases.

the superficial or deep venous system or in both. However, other causes of venous hypertension include venous outflow obstruction, as in post-thrombotic syndrome ${ }^{[1]}$, and severe calf-muscle pump failure owing to paralysis, obesity, or prolonged standing. The increase in venous hydrostatic pressure has peripheral repercussions on the post-capillary venules and capillaries, causing severe hemodynamic changes that affect the arterioles ${ }^{[2]}$. This review focuses on the various pathogenetic mechanisms of stasis microangiopathy triggered by venous hypertension and the currently available treatment options.

\section{STASIS MICROANGIOPATHY: PATHOGENESIS}

\section{Hemodynamic aspects}

Building upon their previous research, in 1990 , Curri et al. ${ }^{[3]}$ showed the presence of microvalves in postcapillary venules and collecting venules and described valvular sclerosis and hyalinosis with consequent loss of function in patients with severe chronic venous insufficiency. In 2006, Caggiati et al. ${ }^{[4]}$ confirmed the existence of these microvalves and hypothesized their role as venular anti-reflux devices in the 
microcirculation. The microvalves are located in venules, and they reach their maximum number in the vessels with a caliber less than 100 microns $^{[2]}$. In 2011 , Vincent et al. ${ }^{[5]}$ showed the incompetence of these valves in patients with severe chronic venous insufficiency using retrograde resin venography. Therefore, venous hypertension is transmitted from the macrocirculation to the microcirculation by the post-capillary venular system. Lesions of microvalves secondary to venous pressure overload lead to the phenomenon of venulo-capillary stasis. The stasis causes a reflex constriction in the pre-capillary arterioles with a blood flow reduction ${ }^{[1]}$. Venulo-capillary stasis causes an increase in endothelial permeability, with opening of the intercellular spaces, slipping of the basement membrane, extravasation of liquids from the capillaries, and interstitial flooding ${ }^{[6]}$. The increased shear stress secondary to venous hypertension causes damage to the glycocalyx that covers the endothelium and consequent activation of inflammatory events, which we discuss in a dedicated $\operatorname{section}^{[7]}$.

\section{The role of the lymphatic system}

The drainage of interstitial fluids is an almost absolute prerogative of the lymphatic circulation, which acts as a "safety valve" against inflammation, removing proinflammatory molecules from interstitium, and edema $^{[8]}$. In fact, edema develops only when the production of interstitial fluid exceeds the drainage capacity of the lymphatic vessels. The increased intra-capillary pressure is initially counteracted by the increase in interstitial pressure, secondary to the accumulation of interstitial fluid, and by the decrease in colloid osmotic pressure, which determines a pressure gradient that favors the entry of liquid into the capillaries. The balance is altered when a condition characterized by a progressive increase in intra-capillary pressure occurs, such as in case of inflammation (e.g., stasis dermatitis and lipodermatosclerosis). At this point, the lymphatic system reacts to avoid edema by increasing its drainage capacity ${ }^{[9]}$. It is interesting to understand why edema still occurs despite this compensation mechanism. Studies with fluorescence microlymphography have shown an obstruction of the superficial lymphatic vessels, a reflux from the deep to the superficial lymphatic system, and an increased capillary permeability ${ }^{[10]}$. Studies with CapiFlow have shown an absence of flow motion and an activation of deep lymphatics due to interstitial hypertension ${ }^{[11]}$. At the histological level, lesions of the anchoring filaments opening the lymphatic vessels and collapses of the lymphatic vessels of the dermis have been reported ${ }^{[6]}$. Other histological studies at the bed of venous ulcer and its edges revealed a severe loss of lymphatic vessels that resulted totally absent in the bed of the ulcer ${ }^{[12]}$. This severe alteration of the lymphatic circulation also causes a localized immune deficit, secondary to loss of immune surveillance, and susceptibility to infections. This finding would provide an explanation for the susceptibility to skin infections observed in patients with chronic venous disease (CVD) at Clinical Etiological Anatomical Pathophysiological (CEAP) classification C6 stage ${ }^{[6]}$.

\section{Hemorheological aspects}

When stasis occurs, there is a marked increase in the aggregation of erythrocytes with consequent obstruction of the capillaries, altered distribution, and slowing of tissue blood flow until it stops. In addition, the erythrocytes lose their discoid shape, transform into spherocytes and echinocytes, and become rigid, with further reduction in tissue blood flow. This phenomenon was described in 1975 by Schmidt and Schombein as "collateral blood viscidation" ${ }^{[13]}$. In this setting, there is an increased erythrocyte diapedesis with deposition of erythrocytes in the interstitium, deposition of hemosiderin, and release of iron, which causes both direct tissue lesions secondary to toxicity and production of free radicals that activate inflammation ${ }^{[14]}$.

\section{The fibrin caps}

In 1982, Burnand et al. ${ }^{[15]}$ showed the presence of fibrin deposits in the pericapillary space secondary to the increased capillary permeability and hypothesized that these "fibrin caps" reduced exchanges between blood and tissues, contributing to the formation of the venous ulcer. However, this hypothesis was rejected by 
other studies which showed that fibrin caps were also present in healed ulcers and that application of Xenon-133 to the skin of patients with fibrin caps had the same clearance as healthy subjects ${ }^{[13,16]}$. Falanga et al. ${ }^{[17]}$ hypothesized that fibrin trapped growth factors, making them unavailable for ulcer healing, thereby delaying reparative processes.

\section{Inflammation}

The lesions of the glycocalyx secondary to the venulo-capillary stasis and the consequent increase in shear stress cause the activation of endothelial mechanoreceptors and the endothelial production of E-selectins that interact with the L-selectins produced by leukocytes, leading to rolling of these cells along the endothelial surface. When leukocytes are activated, they express integrins, which bind to intercellular adhesion molecule 1 (ICAM-1) expressed by endothelial cells, and this event represents the starting point for their migration into the interstitium and for their subsequent degranulation ${ }^{[18-19]}$. The activation of matrix metalloproteinases (MMPs), especially MMP- $2^{[20-22]}$, is a subsequent event. On the other hand, the tissue inhibitor of MMP-2 (TIMP-2) is reduced ${ }^{[20-22]}$. The reduction of TIMP-2 activates inflammation and causes damage to the intercellular matrix by MMPs. The deposition of iron in the tissues further activates the MMPs, which, together with free radicals, accentuate the tissue damage. On the other hand, the production of transforming growth factor $\beta 1$ (TGF- $\beta 1$ ) in the context of inflammation stimulates collagen production leading to fibrosis ${ }^{[14]}$.

\section{Functional alterations}

Inflammation does not spare the peripheral nerves, and for this reason a neuropathy secondary to venous stasis also develops leading to vasomotor changes ${ }^{[23]}$, consisting of abolition of the veno-arteriolar reflex ${ }^{[24]}$, reduction of reactive hyperemia, heating hyperemia, and neuro-mediated vasodilation ${ }^{[25-27]}$. At the level of the venous ulcer, laser Doppler imaging has allowed detecting a high blood flow in the areas with granulation tissue, a low blood flow in the areas without granulation tissue, and a high blood flow both at the edges of the ulcer and at the adjacent areas of lipodermatosclerosis ${ }^{[28]}$. On the other hand, transcutaneous carbon dioxide tension was very low both at the bed of the ulcer and at the edges ${ }^{[29]}$. These two apparently conflicting observations led Partsch to define this condition as "hyperemic hypoxia" [30]. At the capillaroscopic level, different conditions have been described in the areas of lipodermatosclerosis depending on the clinical stage of the ulcer. The initial stages are characterized by a pericapillary halo secondary to increased permeability, a moderate capillary dilation, and capillary tortuosity. In the intermediate stages, the pericapillary halo and capillary dilation are accentuated. The advanced stages are instead characterized by a reduction in the number of capillaries. In the zones of atrophie blanche (white scar tissue), there are avascular areas and few huge and convoluted capillaries. In the ulcerated areas without granulation tissue, there are no capillaries, while, in the areas with granulation tissue, there are few giant capillaries and edema ${ }^{[31-32]}$. The histological examination revealed micro-vessels occlusions, dilation of endothelial junctions, alteration of lymphatic vessels and anchoring filaments, and fibrosis of the interstitial $\operatorname{matrix}^{[23]}$.

\section{STASIS MICROANGIOPATHY: TREATMENT \\ Compression therapy}

It has been reported that compression therapy can significantly improve symptoms and reduce lower limb volume in patients with CVD by improving the function of cutaneous microcirculation ${ }^{[33]}$. Grenier et al. ${ }^{[34]}$ investigated the relationship between skin microcirculatory activities and external compression provided by elastic compression stockings by measuring skin thermal conductivity in a group of 30 female subjects having minor symptoms of CVD (CEAP COS and C1S) and observed an improvement of microcirculatory activities in $83 \%$ of them. 
Compression therapy performed with both bandages and elastic stockings has multiple actions on the microcirculation, such as a reduction in venulo-capillary permeability, an increase in skin capillary perfusion with increased nitric oxide and activation of fibrinolysis, and an increase in cutaneous vasodilation through the activation of capsaicin receptors ${ }^{[33-36]}$. Histological studies have shown that compression reduces edema and venulo-capillary ectasia ${ }^{[37]}$. Studies with CapiFlow ${ }^{[38]}$ have shown a reduced endolymphatic pressure. A reduction in leukocyte adhesion and oxidative stress has also been demonstrated.

\section{Pharmacological therapy}

Two classes of drugs have been shown to significantly interfere with stasis microangiopathy: the purified micronized flavonoic fraction (FFPM) and glycosaminoglycans (GAGs).

FFPM increases sympathetic-mediated venular contractility, reduces leukocyte adhesion by reducing the production of adhesion molecules, and reduces the production of pro-inflammatory molecules. Furthermore, FFPM increases the production of antioxidant factors; reduces the concentration of ICAM-1, vascular cell adhesion molecule 1 (VCAM-1), and vascular endothelial growth factor (VEGF); and reduces the permeability of capillaries.

GAGs (sulodexide and mesoglycan) restore the glycocalyx, activate fibrinolysis by acting on plasminogen activator inhibitor and tissue plasminogen activator, have antithrombotic action by acting on antithrombin and heparin cofactor II, and reduce thrombin-induced platelet aggregation. GAGs also have antiinflammatory action by acting on cytokines, tumor necrosis factor $\alpha$ (TNF- $\alpha$ ), TGF- $\beta 1$, VEGF, and interferon gamma (IFN- $\gamma$ ); blocking chemokines; modulating macrophages; and blocking MMPs (sulodexide) $)^{[2,39,40]}$.

Maresca et al. ${ }^{[41]}$ studied the effect of mesoglycan on cutaneous blood flow measured by laser Doppler fluometry (LDF) in a group of 75 female patients (aged $45.5 \pm 9.6$ years) in different stages of CVD, according to the CEAP classification. The active group $(N=37)$ received mesoglycan $50 \mathrm{mg}$ twice daily in adjunct to standard care. After 90 days of treatment, mesoglycan obtained a significative increase in peak flow at LDF in the entire group of treated women ${ }^{[41]}$. In a systematic review and meta-analysis, Bignamini et al ${ }^{[42]}$ assessed the efficacy and safety of sulodexide for treatment of signs and symptoms of lower extremity CVD. Sulodexide was found to have a beneficial venoactive effect on the major signs and symptoms of CVD such as pain, cramps, heaviness, and oedema, with the exception of discoloration, which appeared unaffected by the treatment. Furthermore, sulodexide was found to be effective in decreasing the release of inflammatory markers present in CVD, such as interleukin-6, monocyte chemoattractant protein1 , soluble intercellular adhesion molecule-1, and free radicals.

Interestingly, it has been shown that vasoactive and anti-inflammatory properties of aminaphtone may be useful in treatment of chronic venous and lymphatic stasis ${ }^{[43]}$. Aminaphtone reduces the expression of endothelial-leukocyte adhesion molecule 1 (ELAM-1), VCAM-1, and ICAM-1, as well as the production of cytokines and vasoconstrictor agent endothelin-1, playing a potential role in treatment of other vascular diseases such as Raynaud's phenomenon ${ }^{[4]}$.

The combination of Ruscus, hesperidin methylchalcone (HMC), and vitamin C has recently been awarded a Grade $1 \mathrm{~A}$ recommendation by the international guidelines ${ }^{[45]}$. A review of clinical studies and a metaanalysis have confirmed its clinical efficacy across a wide spectrum of CVD clinical classes: CoS, C1S, C2, $\mathrm{C} 3$ and $\mathrm{C}^{[46]}$. The combination of Ruscus, HMC, and vitamin $\mathrm{C}$ acts by increasing venous and lymphatic 
tone, protecting microcirculation, and reducing inflammation. In the microcirculation, Ruscus showed a protective effect against histamine-and ischemia/reperfusion-induced leakage in the hamster cheek pouch model, and these effects appeared to involve $\alpha 1$-adrenoreceptors and muscarinic receptors ${ }^{[46-48]}$.

\section{CONCLUSIONS}

Stasis microangiopathy is a pathology with a very complex pathogenesis characterized by the interaction of multiple factors. There are still many areas of uncertainty that need further studies to be fully understood. Treatment of stasis microangiopathy is based on compression therapy and drugs. Compression therapy removes the "upstream" pathological trigger by reducing venous hypertension, which is the "primum movens" of the disease. Drugs, on the other hand, act "downstream" on various hemodynamic, hemorheological, and biochemical factors, which interact and cause the tissue damage that characterizes stasis microangiopathy.

\section{DECLARATIONS}

\section{Authors' contributions}

Literature review, manuscript preparation, review of the manuscript: Bilancini $S$

Literature review, review of the manuscript: Lucchi M

Literature review, review and editing of the manuscript: Ciacciarelli M

\section{Availability of data and materials}

Not applicable.

\section{Financial support and sponsorship}

None.

\section{Conflicts of interest}

All authors declared that there are no conflicts of interest.

\section{Ethical approval and consent to participate}

Not applicable.

\section{Consent for publication}

Not applicable.

\section{Copyright}

(c) The Author(s) 2021.

\section{REFERENCES}

1. Merlen JF, Santeel AM, Robert JL. Post-phlebitic disease, stasis microangiopathy. Phlebologie 1984;37:409-15. (in French)

2. Mansilha A, Sousa J. Pathophysiological Mechanisms of Chronic Venous Disease and Implications for Venoactive Drug Therapy. Int J Mol Sci 2018;19:1669. DOI PubMed PMC

3. Curri SB, Annoni F, Montorsi W. Microvalves in microvenules. Phlebologie 1987;40:795-801. :(in French). PubMed

4. Caggiati A, Phillips M, Lametschwandtner A, Allegra C. Valves in small veins and venules. Eur J Vasc Endovasc Surg 2006;32:44752. DOI PubMed

5. Vincent JR, Jones GT, Hill GB, van Rij AM. Failure of microvenous valves in small superficial veins is a key to the skin changes of venous insufficiency. J Vasc Surg 2011;54:62S-9S. :e1-3. DOI PubMed

6. Mortimer BS, Pearson IC. Lymphatic function in severe chronic venous insufficiency. Phlebolymphology 2004;44:253-257.

7. Secomb TW, Hsu R, Pries AR. Effect of the endothelial surface layer on transmission of fluid shear stress to endothelial cells. Biorheology 2001;38:143-50. PubMed

8. Levick JR. Capillary filtration-absorption balance reconsidered in light of dynamic extravascular factors. Exp Physiol 1991;76:825-57. DOI PubMed

9. Bräutigam P, Vanscheidt W, Földi E, Krause T, Moser E. [Involvement of the lymphatic system in primary non-lymphogenic edema of 
the leg. Studies with 2-compartment lymphoscintigraphy]. Hautarzt 1997;48:556-67. DOI PubMed

10. In: Allegra C, Bartolo M Jr, Carioti G, Carlizza A, Cassiani D, editors. . Microlymphatics in chronic venous insufficiency. Proceedings of the New trends in atherosclerosis vascular diseases and cardiovascular therapy 3rd International Joint Workshop; 1995; Monte Carlo, Monaco.

11. Microlymphatic diameters in mild and severe chronic venous insufficiency. 18th European Conference on Microcirculation; 1994; Rome, Italy. Abstracts. Int J Microcirc Clin Exp 1994;14 Suppl 1:1-262.

12. Eliska O, Eliskova M. Morphology of lymphatics in human venous crural ulcers with lipodermatosclerosis. Lymphology 2001;34:11123. PubMed

13. Cheatle TR, Mcmullin GM, Farrah J, Smith PDC, Scurr JH. Three Tests of Microcirculatory Function in the Evaluation of Treatment for Chronic Venous Insufficiency. Phlebology 1990;5:165-72. DOI

14. Izzo M, Gasbarro V, Coscia V. The role of free iron in cardiovascular diseases. Part II. JTAVR 2017;2:83-95. DOI

15. Browse N, Burnand K. The cause of venous ulceration. Lancet 1982;320:243-5. DOI PubMed

16. Falanga V, Kirsner R, Katz MH, Gould E, Eaglstein WH, McFalls S. Pericapillary fibrin cuffs in venous ulceration. Persistence with treatment and during ulcer healing. J Dermatol Surg Oncol 1992;18:409-14. DOI PubMed

17. Falanga V, Eaglstein W. The "trap" hypothesis of venous ulceration. Lancet 1993;341:1006-8. DOI PubMed

18. Smith PD, Thomas P, Scurr JH, Dormandy JA. Causes of venous ulceration: a new hypothesis. Br Med J (Clin Res Ed) 1988;296:1726-7. DOI PubMed PMC

19. Lawrence MB, McIntire LV, Eskin SG. Effect of flow on polymorphonuclear leukocyte/endothelial cell adhesion. Blood 1987;70:1284-90. PubMed

20. Antignani PL. News in inflammatory and microcirculatory mechanisms. In: Allegra C, Antignani PL, Kalodiki E, editors. News in phlebology. Minerva Medica Ed; 2013. pp. 211-4.

21. Raffetto JD. Dermal pathology, cellular biology, and inflammation in chronic venous disease. Thrombosis Research 2009;123:S66-71. DOI PubMed

22. Raffetto JD, Khalil RA. Matrix metalloproteinases and their inhibitors in vascular remodeling and vascular disease. Biochem Pharmacol 2008;75:346-59. DOI PubMed PMC

23. Gschwandtner ME, Ehringer H. Microcirculation in chronic venous insufficiency. Vasc Med 2001;6:169-79. DOI PubMed

24. Belcaro G, Grigg M, Rulo A, Nicolaides A. Blood Flow in the Perimalleolar Skin in Relation to Posture in Patients with Venous Hypertension. Annals of Vascular Surgery 1989;3:5-7. DOI PubMed

25. Malanin K, Vilkko P, Kolari PJ. Blood flux and venoarteriolar response of the skin in legs with chronic venous insufficiency measured at two different depths by using a double-wavelength laser Doppler technique. Angiology 1998;49:441-6. DOI PubMed

26. Jochmann W, Mostbeck A, Partsch H. Postocclusive reactive hyperemia and postural vasoconstriction in different kinds of leg ulcers investigations with laser Doppler. Vasa 1993;22:306-15. PubMed

27. Bollinger A, Leu AJ, Hoffmann U, Franzeck UK. Microvascular changes in venous disease: an update. Angiology 1997;48:27-32. DOI PubMed

28. Mayrovitz HN, Larsen PB. Periwound skin microcirculation of venous leg ulcers. Microvasc Res 1994;48:114-23. DOI PubMed

29. Dodd HJ, Gaylarde PM, Sarkany I. Skin oxygen tension in venous insufficiency of the lower leg. J R Soc Med 1985;78:373-6. DOI PubMed PMC

30. Partsch H. Investigations on the pathogenesis of venous leg ulcers. Acta Chir Scand Suppl 1988;544:25-9. PubMed

31. Leu AJ, Yanar A, Pfister G, Geiger M, Franzeck UK, Bollinger A. [Microangiopathy in chronic venous insufficiency]. Dtsch Med Wochenschr 1991;116:447-53. DOI PubMed

32. Speiser DE, Bollinger A. Microangiopathy in mild chronic venous incompetence (CVI): morphological alterations and increased transcapillary diffusion detected by fluorescence videomicroscopy. Int J Microcirc Clin Exp 1991;10:55-66. PubMed

33. Klyscz T, Galler S, Steins A, Züder D, Rassner G, Jünger M. [The effect of compression therapy on the microcirculation of the skin in patients with chronic venous insufficiency (CVI)]. Hautarzt 1997;48:806-11. DOI PubMed

34. Grenier E, Gehin C, McAdams E, Lun B, Gobin JP, Uhl JF. Effect of compression stockings on cutaneous microcirculation: Evaluation based on measurements of the skin thermal conductivity. Phlebology 2016;31:101-5. DOI PubMed

35. Wollina U, Abdel-Naser MB, Mani R. A review of the microcirculation in skin in patients with chronic venous insufficiency: the problem and the evidence available for therapeutic options. Int J Low Extrem Wounds 2006;5:169-80. DOI PubMed

36. Pomella F. Microcircolo e malattia venosa cronica. In: Bilancini S (Italian Society for Microcirculation), editor. Le acrosindromi vascolari e non solo. Ed. Minerva Medica. Forthcoming 2021. (in Italian).

37. Ivkov-Simić M, Duran V, Matić M, Gajinov Z, Jovanović M, Matović L. Chronic venous insufficiency and compression therapy. Med Pregl 2001;54:69-74. :(in Croatian). PubMed

38. In: Allegra C, Oliva E, Sarcinella R, editors. Hemodinamic modifications induced by compression therapy in CVI evaluated by microlymphography. XII Congress Union Internationale de Phlébologie. 1995; London, UK. Phlebology 1995;Suppl 1:1138-49.

39. Barros B, Kakkos SK, De Maeseneer M, Nicolaides AN. Chronic venous disease: from symptoms to microcirculation. Int Angiol 2019;38:211-8. DOI PubMed

40. Raffetto JD, Eberhardt RT, Dean SM, Ligi D, Mannello F. Pharmacologic treatment to improve venous leg ulcer healing. J Vasc Surg Venous Lymphat Disord 2016;4:371-4. DOI PubMed

41. Maresca L, Foggia C, Leonardo G. Restoring microvascular efficiency with mesoglycan in women affected by moderate chronic venous disease. Minerva Cardioangiol 2015;63:105-11. PubMed

42. Bignamini AA, Matuška J. Sulodexide for the Symptoms and Signs of Chronic Venous Disease: A Systematic Review and Meta- 
analysis. Adv Ther 2020;37:1013-33. DOI PubMed PMC

43. De Anna D, Mari F, Intini, S, Gasbarro V, Sortini A, et al. Effects of therapy with aminaftone on chronic venous and lymphatic stasis. Minerva Cardioangiol 1989;37:251-4. PubMed

44. Ruaro B, Pizzorni C, Paolino S, Alessandri E, Sulli A. Aminaphtone Efficacy in Primary and Secondary Raynaud's Phenomenon: A Feasibility Study. Front Pharmacol 2019;10:293. DOI PubMed PMC

45. Nicolaides A, Kakkos S, Baekgaard N, et al. Management of chronic venous disorders of the lower limbs. Guidelines According to Scientific Evidence. Part I. Int Angiol 2018;37:181-254. DOI PubMed

46. Kakkos SK, Guex JJ, Lugli M, Nicolaides AN. CEAP clinical classes C0S-C4: differences, similarities and role of Ruscus + HMC + vitamin C in patients with chronic venous disease. Int Angiol 2020;39:118-24. DOI PubMed

47. Bouskela E, Cyrino FZ, Marcelon G. Possible mechanisms for the inhibitory effect of Ruscus extract on increased microvascular permeability induced by histamine in hamster cheek pouch. J Cardiovasc Pharmacol 1994;24:281-5. PubMed

48. Rauly-Lestienne I, Heusler P, Cussac D, Lantoine-Adam F, de Almeida Cyrino FZG, Bouskela E. Contribution of muscarinic receptors to in vitro and in vivo effects of Ruscus extract. Microvasc Res 2017;114:1-11. DOI PubMed 